\title{
IMPLEMENTASI SINGLE MINUTE EXCHANGE OF DIES (SMED) UNTUK PERBAIKAN PROSES BRAND CHANGEOVER MESIN FOCKE DAN PROTOS
}

\author{
Ade Astuti Widi Rahayu ${ }^{1}$ \\ ${ }^{1}$ Jurusan Teknik Industri, Fakultas Teknik dan Ilmu Komputer, Universitas Buana Perjuangan Karawang \\ Jl. HS. Ronggowaluyo Telukjambe Timur Karawang, \\ Email:ade.widiastuti@ubpkarawang.ac.id
}

\begin{abstract}
The setup process at the time of brand change (Brand Changeover) that often occurs in machines has an impact on small performance values and the potential for delays in the distribution schedule so that in these conditions stock outs occur in the market and cannot meet consumer needs according to the schedule that has been set. So that it is necessary to pay attention and observe the brand transfer activities on the maker and packer machines so that these activities are more efficient. From the results of the analysis, it is known that the brand change process that occurs in the SPM area takes a long time. With the process of separating external and internal activities with the SMED method, and paralleling internal activities in a process, it is expected to be able to improve production performance. The average time required for the protos machine to make a brand change is 85,078 minutes and the Focke engine is 179,105 minutes. The SMED method and separating external and internal activities can reduce $27.834 \%$ Brand Change time for Protos machines and $42.243 \%$ Brand Change time for Focke machines. From the implementation of this method for 7 weeks, it can be seen that the reduction in Brand change time can increase the machine's Link Up uptime performance by $6.48 \%$.
\end{abstract}

Keywords: Brand Changeover, SMED, Lean

\begin{abstract}
ABSTRAK
Waktu pergantian brand merupakan salah satu waste yang perlu kurangi. Proses setup pada saat perpindahan brand (Brand Changeover) yang sering terjadi pada mesin berdampak pada nilai perfoma yang kecil dan berpotensi terjadi keterlambatan jadwal distribusi sehingga pada kondisi tersebut terjadi stock out pada pasar dan tidak dapat memenuhi kebutuhan konsumen sesuai dengan jadwal yang telah di tetapkan. Sehingga hal tersebut perlu diperhatikan dan di lakukan observasi terhadap kegiatan perpindahan brand pada mesin maker dan packer agar kegiatan tersebut lebih efisien. Dari hasil analisa, diketahui bahwa proses pergantian brand yang terjadi di area SPM memakan durasi waktu yang cukup lama. Dengan proses pemisahan kegiatan eksternal dan internal dengan metode SMED, dan memparalelkan kegiatan internal dalam suatu proses di harapkan mampu meningkatkan perfoma produksi. Waktu rata-rata yang dibutuhkan mesin protos untuk melakukan brand change adalah 85.078 menit dan mesin Focke adalah 179.105 menit. Dengan methode SMED dan melakukan pemisahan kegiatan eksternal dan internal dapat mengurangi 27.834\% waktu Brand Change untuk mesin Protos dan $42.243 \%$ waktu Brand Change untuk mesin Focke. Dari implementasi metode tersebut selama 7 minggu dapat diketahui bahwa penurunan waktu Brand change dapat meningkatkan peforma uptime Link Up mesin sebesar $6.48 \%$.
\end{abstract}

Kata kunci : Brand Changeover, SMED, Lean

\section{PENDAHULUAN}

Dalam menghadapi persaingan usaha yang semakin berat dan tuntutan ekonomi global yang semakin ketat, maka setiap perusahaan dituntut untuk mampu bersaing dan melakukan improvement demi kesejahteraan semua pihak yang terkait di dalam perusahaan tersebut. Dengan semakin pesatnya perkembangan ilmu pengetahuan dan tehnologi pada saat ini tentu dapat membantu pihak perusahaan 
untuk memenuhi permintaan konsumen secara cepat namun dengan tetap menjaga kualitas produknya. Perusahaan yang mampu memberikan pelayanan serta kualitas barang yang sangat baik bagi konsumen akan memiliki reputasi yang baik di bandingkan kompetitornya. Oleh sebab itu perusahaan harus memiliki strategi untuk mempertahankan, memperbaiki serta mampu meningkatkan pelayanan terhadap konsumen. Salah satu cara yang dapat di lakukan perusahaan yaitu dengan meningkatkan produktivitas dan memenuhi kebutuhan pelangan dengan cepat. Perbaikan proses produksi harus di lakukan secara countinous improvement agar pemborosan dapat diperkecil. (Ashmore, 2001).

Perkembangan ilmu pengetahuan dan daya dunia industri yang kompetitif memberikan banyak sekali konsumen pilihan produk detail yang spesifik sesuai dengan keinginan dan harapan para konsumen. Hal tersebut dapat memberikan impact terhadap perilaku dan ekspektasi dari konsumen, hal tersebut dapat memicu suatu perilaku baru pada dunia manufacturing saat ini. Dampak dari perilaku konsumen tersebut mengharuskan produsen memproduksi barang dalam jumlah yang sedikit dan memiliki berbagai varian untuk mengisi pasaran saat ini untuk mempertahankan konsumen agar tetap memilih produknya. Beberapa upaya untuk mencapai tujuan tersebut perusahan mentargetkan untuk mengurangi waktu setup atau fine tuning untuk mencapai tujuan tersebut PT. ITC adalah salah satu perusahaan rokok terkemuka di dunia yang memiliki sekitar 449 varian brand SKU (Stock Keeping Unit)) dengan 31 negara pasar tujuan. Perusahan tersebut memiliki beberapa variant mesin untuk membuat produk jadi dalam 1 case yang akan di kirim ke konsumen.

Brand Change tersebut telah terjadwalkan oleh PPIC selama 1 bulan kedepan tergantung kebutuhan market dan juga negara tujuan export produk. Proses tersebut memiliki peranan yang sangat penting dalam menjaga stock di pasaran dan juga sebagai tolok ukur performa suatu link up terutama pada Departemen Business Unit yang mulai memproduksi brand eksport sejak Oktober 2012. Jumlah unit yang digunakan untuk memenuhi kebutuhan market export ada 12 link up. Satu Link Up terdairi dari 2 mesin utama yaitu focke sebagai packer dan protos sebagai maker cigarette. Dari hasil pengamatan beberapa minggu di lapangan tercatat waktu rata-rata yang dibutuhkan dalam satu link up adalah 162.71 menit. Waktu tersebut di peroleh dari laporan waktu rata-rata yang dibutuhkan dalam proses brand change. Jika waktu brand change dan finetunning mesin dalam proses brand change dapat di kurangi diharapkan dapat meningkatkan performa dari link up tersebut. Akibat yang ditimbulkan dari lamanya proses tersebut adalah menurunya performa suatu link up dalam tiap minggu, pencapaian performa di 4 minggu pengamatan hanya sekitar $25.70 \%$. Angka tersebut $25.70 \%$ masih sangat jauh di bawah target tahun 2015 yaitu 56\%. (sumber: Data perusahaan 2015).

Berdasarkan informasi yang penulis peroleh dari pihak management, karena lamanya proses pergantian brand tersebut dapat mempengaruhi uptime, biaya produksi, ditribusi, bahkan sampai stock out di market juga bisa menganggu planing pada minggu selanjutnya. Pada penilitian kali ini penulis akan membahas bagaimana caranya memperbaiki proses brand change tersebut dengan metode Single minutes exchange of dies (SMED). Hasil dari penerapan metode tersebut adalah untuk dapat mereduksi waktu setup pada saat melakukan brand change, dan digunakan untuk memisahkan aktivitas -aktivitas internal dan eksternal dalam proses tersebut. Alasan penulis memilih metode SMED karena metode ini dapat menganalisa permasalahan pada saat brand change sehingga dapat meningkatkan uptime suatu link up. Dari hasil pemisahan kegiatan tersebut dapat pula kita lakukan analisa SOP yang tepat dalam melakukan kegiatan tersebut sehingga dapat memperoleh waktu yang optimal dalam melakukan suatu kegiatan sehingga harapannya dapat meningkatkan performa dan output produksi yang optimal. Sebagai tambahan untuk mengurangi resiko customer complaint yang terjadi karena proses tersebut penulis kan membuatkan saran untuk pembuatan OPL (One point Lesson) prosedur clearing. (sumber: Data perusahaan 2017).

Berdasarkan latar belakang, maka permasalahan dapat di rumusan sebagai berikut. Metode SMED ini merupakan metode yang akan penulis gunakan sebagai pendekatan dalam upaya mereduksi waktu setup mesin dan mengeliminasi kegiatan yang kurang produktif pada saat proses brand change: Bagaimana mengetahui waktu yang di digunakan pada saat brand change pada suatu Link Up.

Apa penyebab terjadinya mix up product.

Bagaimana upaya yang dapat dilakukan untuk mereduksi waktu pada saat proses brand change. 


\section{Tujuan Penelitian}

Adapun beberapa tujuan dilakukannya penelitian ini adalah sebagai berikut:

Untuk mengetahui waktu brandchange saat ini di dalam satu Link Up.

Untuk mengetahui penyebab mixup produk.

Untuk memberikan saran masukan terhadap perusahaan saat melakukan proses brand change.

"Lean manufacturing populer dengan sebutan Just-In-Time Manufacturing yang telah dikembangkan oleh Toyota. Konsep tersebut sekarang digunakan oleh berbagai industry manufacturing dan bisnis yang meliputi engineering, administrasi, manajemen dan proyek. Lean manufacturing memiliki tujuan untuk mengubah suatu organisasi menjadi lebih efisien, dan berjalan dengan lancar, serta kompetitif. Aplikasi dari lean yaitu mengurangi lead time dan meningkatkan produktivitas dengan menghilangkan waste yang timbul dalam berbagai bentuk."(Gaspersz, 2011).

\section{SMED (Single-Minute Exchange of Dies)}

SMED adalah salah satu metoda improvement dari Lean Manufacturing yang digunakan untuk mempercepat waktu yang dibutuhkan untuk melakukan setup pergantian dari memproduksi satu jenis produk ke model produk lainnya. Waktu pergantian setup adalah salah satu bentuk WASTE / PEMBOROSAN dalam konsep Lean yang harus dihilangkan karena tidak memberi nilai tambah untuk pelanggan dan mengakibatkan proses tidak efisien. Ada beberapa istilah lain dari SMED yaitu QCO (Quick Change Over), 4SRS (Four Step Rapid Setup), Setup Reduction, OTS (One Touch Setup), dan OTED (One Touch Exchange of Die) yang kesemuanya mengacu pada hal yang sama yaitu sebuah strategy untuk mempercepat waktu setup pergantian produk. Kata "Single Minute" bukan berarti bahwa lama waktu setup hanya membutuhkan waktu satu menit, tapi membutuhkan waktu di bawah 10 menit (dengan kata lain single digit minute).

Waktu setup sendiri didefinisikan sebagai lama waktu yang dibutuhkan saat produk baik terakhir selesai sampai produk baik pertama keluar. Jadi didalam waktu setup ada waktu organizational seperti menghentikan mesin dan memanggil maintenance, melakukan persiapan peralatan setup, waktu setup, changeover, dan startupnya sendiri, melakukan adjustment, trial run sampai menghasilkan produk baik pertama. Aktifitas-aktifitas tersebut yang berpeluang untuk dipercepat sehingga proses setup changeover lebih effisien. Meskipun pada awalnya metode SMED ini dipakai di industri otomotif, pada perkembangannya metode ini digunakan pada berbagai macam industri manufactur seperti electronics, semicon, packaging, dll. Bahkan konsep dan pemikiran SMED ini dapat diterapkan di berbagai macam tipe industri.

Shigeo Shingo (1985), mengembangkan sebuah metodologi untuk menganalisa dan mereduksi waktu changeover yang disebut dengan sistem SMED, dan tahapan-tahapan implementasinya dijelaskan sebagai berikut:

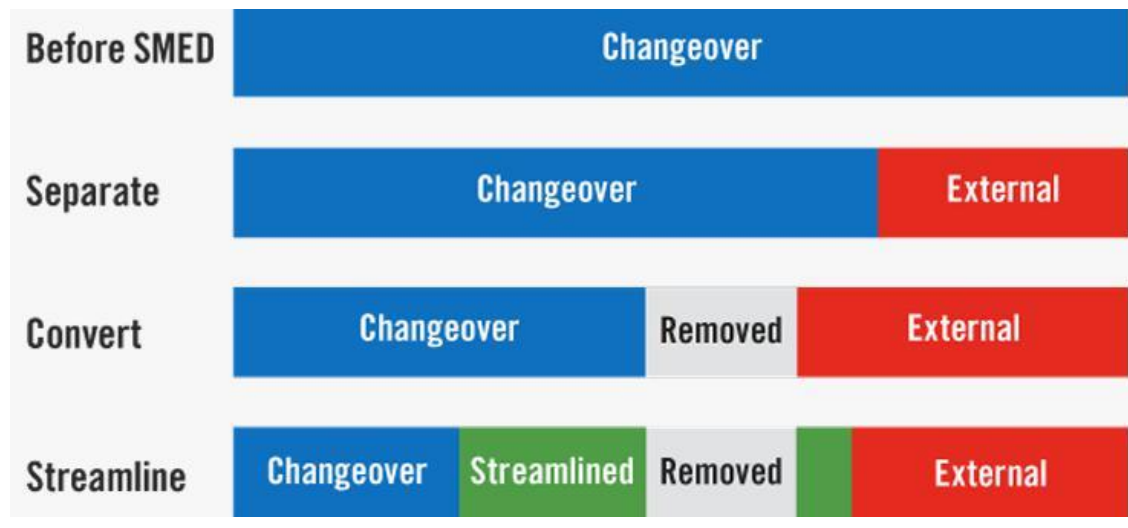

Gambar 1. Empat tahap utama dalam implementasi SMED 


\section{METODE PENELITIAN}

Penelitian ini bertujuan untuk mengevaluasi proses brand change dengan melakukan identifikasi kegiatan pada saat proses brand change kegiatan eksternal dan internal dengan mengunakan pendekatan single minutes exchange of dies (SMED). Untuk mencapai tujuan tersebut, maka di berikan beberapa penjelasan sebagai berikut yang terkait dengan langkah-langkah penelitian. Langkah-langkah tersebut antara lain adalah sebagai berikut:

\section{Jenis Disain Penelitian}

Penelitian ini dilakukan pada departement busines unit Export. Analaisa proses ini mengunakan konsep Laen manufacturing dengan metode SMED, yang di mulai melakukan observasi yang di fokuskan pada pengumpulan data waktu proses brand change, data kegiatan brand change dan klasifikasi kegiatan brand change.

Adapun jenis-jenis disain penelitian meliputi:

Identifikasi masalah dan tujuan penelitian

Menelusuri sumber-sumber kepustakaan

Melakukan observasi dan wawancara

Melakukan analisis data

Menginterpretasikan antara kondisi penelitian dengan data yang diperoleh

Memberikan rekomendasi perbaikan

\section{Teknik Pengumpulan Data}

Teknik pengumpulan data yang digunakan dalam penelitian ini adalah teknik studi kasus. Data dikumpulkan untuk mengukur proporsi waktu dan langkah-langkah dalam setiap proses yang dapat di klasifikasikan menjadi kegiatan eksternal dan kegiatan internal. Namun sebelumnya wawancara kepada pakar guna mengetahui permasalahan yang ada dalam proyek. Dalam hal ini diberikan pertanyaan kepada 4 orang yang memiliki pengalaman di bidangnya untuk memperoleh data yang berhubungan dengan hal yang mempengaruhi waktu proses brand change over.. Kemudian memberikan solusi dan saran untuk mengurangi waktu setup dan proses brand change.

\section{Metode Pengolahan Data}

Penelitian ini bertujuan untuk mengetahui waktu standard, metode kerja operator maintenance dalam melakukan setup mesin, kapasitas produksi, dan tingkat efektivitas produksi pada mesin facke dan Hauni. Data yang telah didapatkan dari hasil pengumpulan data dilapangan selanjutnya akan dilakukan pengolahan data menggunakan pendekatan dengan metode Single-Minute Exchange of Dies (SMED) untuk mengetahui apa saja aktivitas yang dilakukan operator saat melakukan setup mesin dan kemudian dilakukan perbaikan menggunakan pendekatan metode tersebut. Tahapan umum dalam pengolahan data adalah sebagai berikut:

Menghitung waktu normal dan waktu rata-rata untuk tiap data waktu changeover yang berdasarkan dari hasil pengumpulan data.

Analisis Menggunakan SMED

Langkah pendahuluan Mendeskripsikan kegiatan dan aktivitas yang dilakukan operator saat melakukan setup mesin tanpa membedakan aktivitas kerja antara aktivitas internal dan eksternal

Langkah pertama memisahkan internal setup dan eksternal setup. Internal setup merupakan proses setup pada saat mesin berhenti beroperasi, sedangkan eksternal setup merupakan proses setup saat mesin sedang beroperasi. Gunakan checklist untuk semua komponen dari setiap langkah dalam proses produksi.

Langkah kedua mengubah internal setup menjadi eksternal setup. Cara mengubah internal setup menjadi eksternal setup sebagai berikut:

Lakukan langkah pemeriksaan kembali pada setiap proses operasi untuk melihat apakah ada langkah yang salah sehingga diasumsikan sebagai internal setup.

Temukan cara untuk mengubah langkah tersebut menjadi eksternal setup.

Langkah ketiga perampingan semua aspek operasi, dengan cara melakukan perbaikan internal setup dengan cara continous improvement dengan tujuan untuk meminimalkan waktu setup internal sehingga waktu berhenti mesin dapat dikurangi.

Menghitung dan membandingkan waktu rata-rata setup mesin sebelum dan setelah improvement. 


\section{HASIL DAN PEMBAHASAN}

Pada penelitian berikut ini berfokus pada Link up 23 yang memiliki frekuensi brand change over paling banyak dalam setiap harinya. Pada link up tersebut memiliki beberapa variant produk export sekitar $40 \%$ dari variant export PT. International Tobacco itu sendiri sehingga di haruskan dalam melakukan proses brand change secepat mungkin untuk menghindari produk stock out dan juga mengurangi biaya pengiriman menggunakan air fright cost karena keterlambatan produk yang akan mengakibatkan penurunan profit perusahaan.

Dalam suatu link up biasanya terdiri dari beberapa mesin yang saling terhubung. Link up 23 terdiri atas 1 mesin Packer dan 1 mesin maker, dalam link up tersebut di bagi atas beberapa unit yang memiliki fungsi yang berbeda beda antara unit satu dengan yang lainnya, diantaranya adalah Max, $S E$, High Lid, Wrapper,Boxer, dan Cortoner. Pada Link up produksi tersebut merupakan proses yang mengalir dari hulu ke hilir yang sering di sebut flow process produksi, pada link up tersebut masuk pada departemen secondary processing, produk pada awalnya di prosess pada primary processing kemudian di transfer ke secondary kemudian di proses mesin maker dan di transfer melalui coveyor untuk di proses mesin packer yang selanjutnya akan di kirim ke Finish Good melalui Conveyor.

\section{Overall Process Flow Chart For The Factory}

Berikut adalah gambaran Flow process secara keseluruhan di produksi

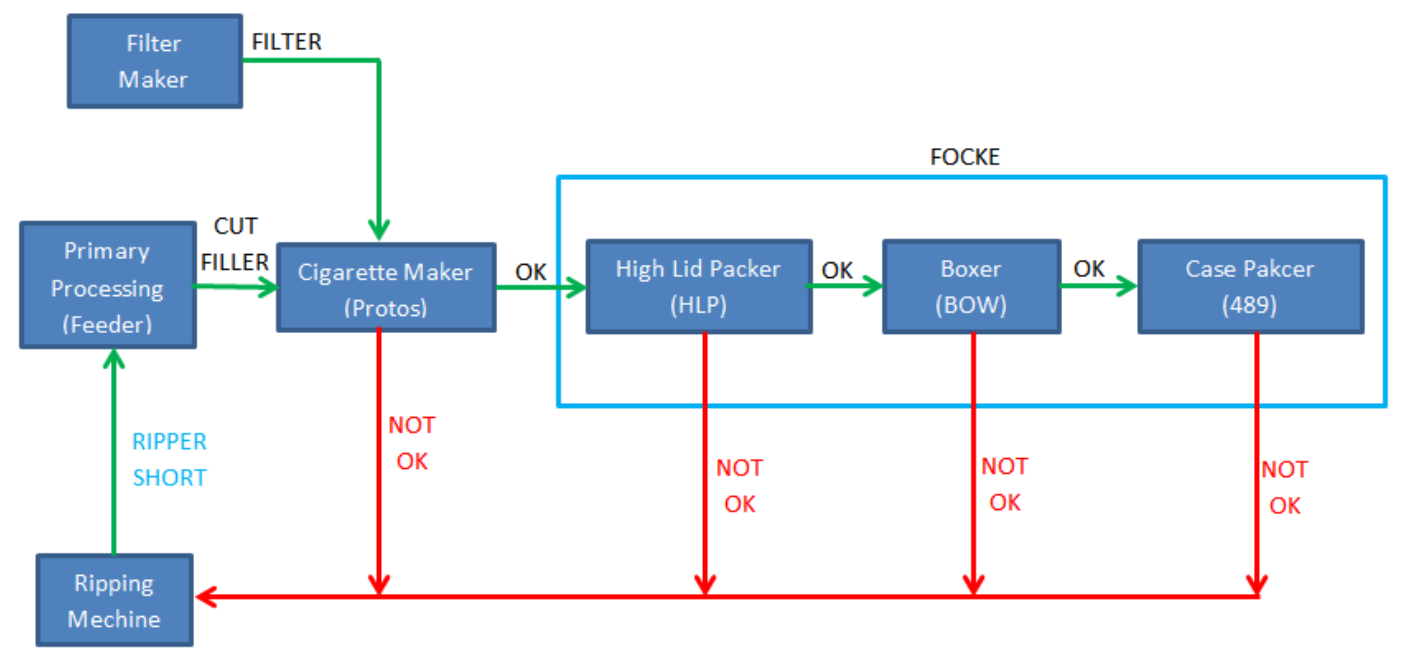

\section{Gambar 2. Overall Process on Floor}

Primary Processing ( Feeder)

Proses awal pengolahan dari bahan dasar yang akan di gunakan pada saat proses produksi berupa tembakau yang di proses dan di cacah sesuai dengan spesifikasi yang telah di tentukan oleh PD.

Cigarette Maker

Pada proses ini terjadi pengolahan bahan dasar (tembakau) di gabungkan dengan material pendukung lainnya diantaranya adalah tipping paper, cigarette paper dan filter cigarette melalui beberapa tahapan proses yang berkelanjutan.

Filter Maker

Pada tahap ini proses pembuatan filter cigarette yang akan di kirim ke cigarette maker dengan menggunakan filter shutter untuk di proses menjadi cigarette di mesin maker.

Ripping Machine

Pada mesin ini semua reject dari mesin feeder maker cigarette, HLP, BOW, dan 489 akan di kirim dan di proses di mesin ripping untuk di pisahkan anata tembakau dan material non tembakau agar tembakau dapat di proses dan di gunakan kembali untuk bahan dasar produksi High Lid Packer (HLP) 
Pada proses ini cigarette dari maker di transfer ke HLP melalui RTS cigarette kemudian di bungkus sesuai jumlah yang telah di tetapkan dengan tambahan material pendukung seperti, Alufoil, inner frame dan Blank untuk di bentuk sesui dengan spesifikasi mesin

Boxer (BOW)

Pada proses ini packet dari HLP di transfer ke mesin BOW melalui Reservoir dan mesin wrapper, pada saat ini terjadi penambahan, pita cukai, packet wrap dan slof forming packet.

a. Case Packer(489)

Pada mesin ini Slof dari packet BOW di transfer melalui conveyor menuju 489, untuk proses pemberian Bundle lable dan case lable untuk di tracking code date produksinya.

\section{Pengolahan data Proses Brand Changeover}

Dari data informasi yang telah di kumpulkan penulis ada masalah terkait lamanya proses brand changeover di produksi yang telah penulis rangkum mengunakan diagram cause and impact

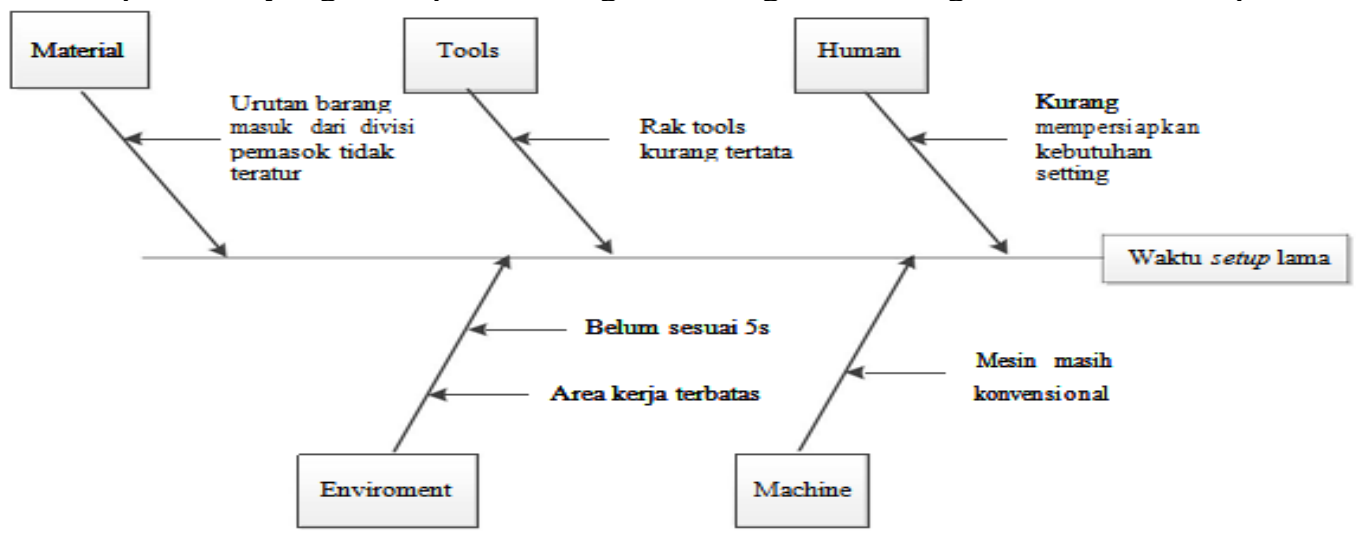

\section{Gambar 3. Diagram Tulang Ikan Waktu Set Up}

Berikut adalah data kegiatan pada saat brand change dan cara penghitungan waktu siklus di mesin protos.

Perhitungan waktu Standar atau siklus rata- rata proses di mesin Protos:

$$
W_{s}=\frac{\sum X_{i}}{N}
$$

Ws $\quad=$ Waktu standar

$\sum x i \quad=$ Jumlah data kegiatan seluruh sample

$N \quad=$ Banyaknya sample dalam suatu aktivitas

Ws $\quad=\frac{3259.6}{30}=105.65$

Kemudian diberikan data kegiatan pada saat brand change dan cara penghitungan waktu siklus di mesin Focke.

Perhitungan waktu Standar atau siklus rata- rata proses di mesin Focke:

$$
W_{s}=\frac{\sum X_{i}}{N}
$$

Ws $=$ Waktu standar

$\sum x i=$ Jumlah data kegiatan seluruh sample

$N=$ Banyaknya sample dalam suatu aktivitas 
$W s=\frac{1949.9}{30}=62.9$

Berikut diberikan grafik penurunan durasi brand change over setelah SMED:

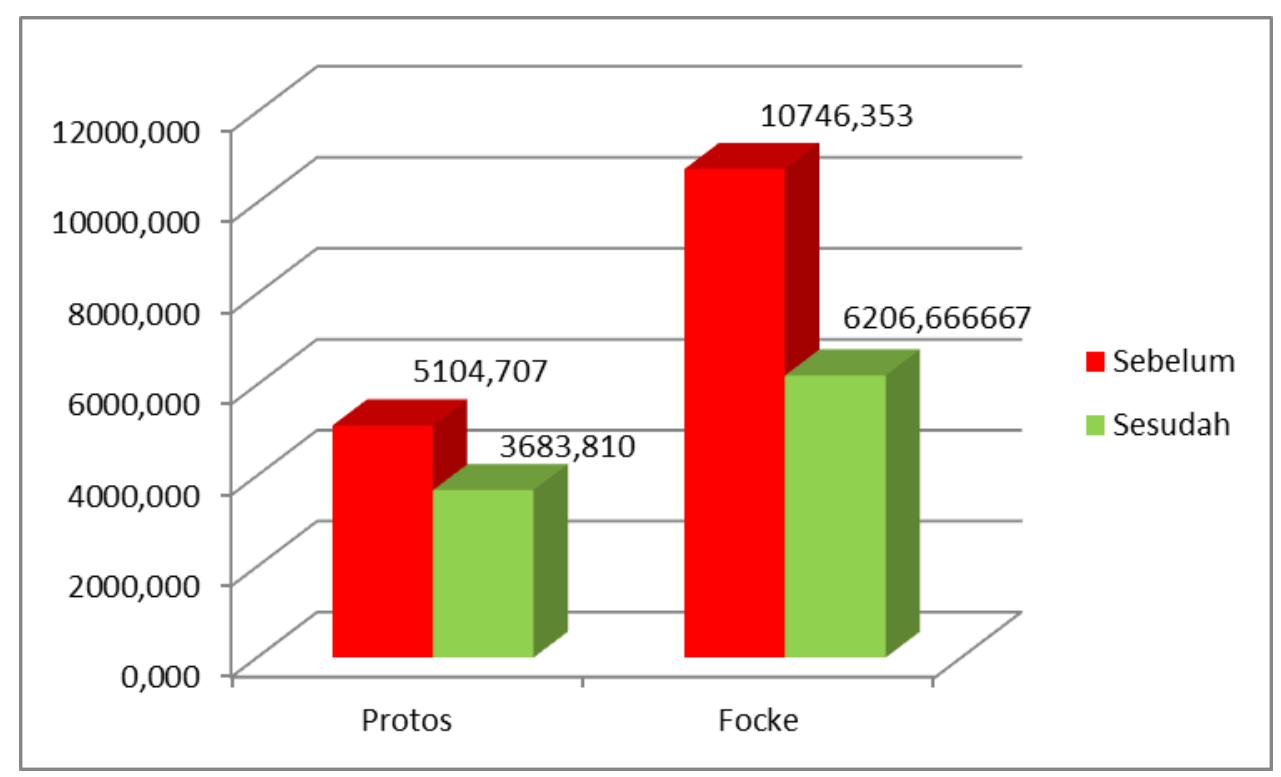

Gambar 4. Grafik Perbandingan Waktu Brand change

Setelah penerapan SMED pada saat proses brand change over dari hasil pengamatan selama 7 minggu dan hasil pengamatan kegiatan proses brand change rutin terhadap mesin protos dan focke sebelum menerapkan SMED, waktu rata-rata proses brand change protos adalah 85.078 menit dan focke adalah 179.105 menit. Setelah melakukan improvement waktu yang di capai mesin protos adalah 61. 397 menit dan pada mesin focke adalah 103.444 menit. Hal tersebut menunjukan perbedaan waktu yang cukup signifikan, improvement tersebut mampu mengurangi durasi waktu sekitar 27.834\% waktu Brand Change untuk mesin protos dan $42.243 \%$ waktu brand change untuk mesin focke.

\section{KESIMPULAN DAN SARAN}

Berdasarkan dari tujuan yang sudah dibahas pada sub bab pertama, maka dapat di peroleh kesimpulan dari penilitian yang dilakukan penulis sebagai brikut:

Berdasarkan penelitian yang telah di lakukan terhadap objek penelitian, setelah penerapan SMED pada saat proses brand change over dari hasil pengamatan selama 7 minggu dari hasil pengamatan kegiatan proses brand change rutin terhadap mesin protos dan focke sebelum menerapkan SMED waktu rata-rata proses brand change protos adalah 85.078 menit dan focke adalah 179.105 menit. Setelah melakukan improvement dengan metode SMED waktu yang di capai mesin protos adalah 61 . 397 menit dan pada mesin focke adalah 103.444 menit. Hal tersebut menunjukan perbedaan waktu yang cukup signifikan pada improvement tersebut karena mampu mengurangi durasi waktu sekitar $27.83 \%$ untuk waktu Brand Change untuk mesin protos dan $42.24 \%$ waktu brand change untuk mesin focke.

Pada saat penelitian berlangsung penulis menemukan beberapa lokasi yang terlewat untuk dilakukan clearing mesin sehingga berpotensi terhadap terjadinya mix up produk pada saat mesin tersebut digunakan untuk memproduksi brand yang berbeda sehingga penulis memberikan saran untuk pembuatan warning sign pada area-area tertentu dan pembuatan check list Report lokasi potensial yang dapat meningkatkan resiko mix up produk. 
Dari hasil penelitian penulis memiliki saran yang dapat di terapkan perusahaan pada saat melakukan brand changeover agar dapat meningkatkan kualitas dan produktivitas produksi yaitu sebagai berikut:

Melakukan analisa data dan pemisahan aktivitas

Melakukan paralel kerja pada saat mesin brand change

Melakukan improvement proses brand change dengan metode SMED.

\section{DAFTAR PUSTAKA}

Ashmore, C. (2001). Kaizen and the art of motorcycle Manufacture. Engineering management Journal 11, 211-214

Gaspersz, V. (2007). Lean Six Sigma for Manufacturing and Service Industries. Jakarta : PT. Gramedia Pustaka Utama.

Shingo, S. (1985). A Revolution in Manufacturing: The SMED System. Cambridge: Productivity Press. 